\title{
Persistent asthma: disease control, resource utilisation and direct costs
}

\author{
E. Van Ganse*, L. Laforest*, G. Pietri*, J.P. Boissel ${ }^{\#}$, F. Gormand ${ }^{\oplus}$, R. Ben-Joseph ${ }^{+}$, P. Ernst ${ }^{\S}$
}

Persistent asthma: disease control, resource utilisation and direct costs. E. Van Ganse, L. Laforest, G. Pietri, J.P. Boissel, F. Gormand, R. Ben-Joseph, P. Ernst. (C)ERS Journals Ltd 2002.

ABSTRACT: Despite evidence that adverse outcomes are less frequent when asthma management is optimised, the link between the level of control, disease severity and medical resource utilisation (MRU) is poorly documented. This relationship was investigated in a group of patients suffering from persistent asthma (Global Initiative for Asthma (GINA) $\geqslant 2$ ) in France.

In 1998 a computerised family practice database was used to identify asthma patients aged 17-50 yrs. Information from the database was complemented by a patient survey to retrospectively assess the level of asthma control and hospital contacts. Costs of MRU over a 12-month study period were related to demographics, medical history, asthma control, and doses of inhaled corticosteroids prescribed during the prestudy period.

A review of the computerised medical database identified 1,038 adult patients with persistent asthma, who completed the survey questionnaire. Over a 12-month period, the mean cost of MRU was $549.8 €$ for well-controlled patients, $746.3 €$ per patient with moderate control, and $1,451.3 €$ per patient with poor control. Costs also increased significantly with age, access to free asthma care, comorbid conditions, asthma symptoms in the past year and whether inhaled corticosteroids had been prescribed before the study period.

In patients with persistent asthma, large differences were observed in the use of medical resources according to control and severity. Therefore, if patients appropriately use prescribed control therapy, their use of medical resources may be reduced. Eur Respir J 2002; 20: 260-267.
*Pharmacoepidemiology Unit, EA643 and Poison Centre, ${ }^{\#}$ Clinical Pharmacology Unit, EA643, Claude-Bernard University and "Respiratory Medicine, South Lyon Hospital Centre University Hospital, Lyon, France. ${ }^{+}$Merck \& Co., Inc., Whitehouse Station, NJ, USA. ${ }^{\S}$ Pharmacoepidemiology Unit, McGill University, Montreal, Canada.

Correspondence: E. Van Ganse, Centre Antipoison, Centre de Pharmacovigilance, Pavillon N, Hôpital Edouard Herriot, Lyon 69347 Cedex 03, France. Fax: 33472666444

E-mail: eric.vanganse@chu-lyon.fr

Keywords: Asthma, control, health economics, resource utilisation, severity, therapy

Received: December 122001

Accepted after revision: April 42002

The Pharmacoepidemiology Unit is part of the EA643 (Claude-Bernard University, Lyon, France) and of the Poison Centre (E. Herriot Hospital, Lyon, France). The study was supported by the Biomed grant $\mathrm{Nr}$ BMH4 CT965033 and by Merck \& Co., Inc., Whitehouse Station, NJ, USA.
Two factors should be distinguished in asthma: the degree of disease severity and the level of control achieved by the patient [1]. Asthma severity can be considered as an intrinsic and rather stable characteristic of the disease for a given patient, i.e. the maximal level of impairment that asthma can bring to that patient, up to and including death; it is unclear how severity is affected by therapy [2]. One way to assess severity is the level of corticosteroid prescription, inhaled or oral [3]. By contrast, the level of control varies with time; it is primarily determined by contacts with allergens or infectious agents, and by therapy [4]. In theory, the level of control can be influenced by patients, since they may influence two determinants of control, i.e. exposure to asthma triggers and adequate use of prescribed therapy. Control can also be influenced by how the healthcare system recognises and responds to patients who receive suboptimal therapy [5].

Many studies suggest that, on average, asthma patients do not use controller medicines optimally and that the resulting undertreatment puts the patient at risk of adverse outcomes, including asthma exacerbations, unscheduled visits to the consulting room, emergency room (ER) contacts and hospitalisations. A recent study identified additional risks factors for visits to the ER by asthma patients: absence of predetermined crisis plan, previous visits to ER facilities, and inadequate use of prophylactic medicines during a flare-up of an exacerbation [6]. Poor compliance with controller medicines has been identified as a major determinant of hospitalisation due to asthma [7]. Drug-utilisation studies have shown that medical resource utilisation (MRU) is increased threefold among high users of inhaled $\beta$-agonists. Furthermore, among these patients, hospital costs appear to be determined by disease severity [8]. In their study, LANES et al. [9] found that $8 \%$ of asthma patients had either a hospital admission or an ER visit during a 12month study period; their hospital costs accounted for $25 \%$ of the total costs of asthma care.

While studies confirm that a minority of patients 
use the majority of medical resources for asthma, the relationship between the use of medical resources and either control or severity needs clarification [10]. Also, it is unclear whether the relationship between control and MRU varies according to the degree of asthma severity. The present study examined MRU in adult patients with persistent asthma in France. The objectives were to provide descriptive information about direct cost of asthma care, and to identify variables related to the costs of MRU, with a specific emphasis on the relationship between cost and level of control and its variation according to asthma severity.

\section{Materials and methods}

\section{Data sources}

Individual patient data were obtained from a computerised database, which was complemented by a patient survey. Details of study methods have been published previously and are summarised here [3]. Patients agreed to participate after receiving written information on the study.

Computerised database. BKL-Thalès, a computerised database of patients of French general practitioners (GPs) was accessed in early 1998. GPs who agreed to participate were located throughout the French territory. Patients with persistent asthma (Global Initiative for Asthma (GINA) stage $\geqslant 2$ ) were identified in the database according to the following criteria: age 6-50 yrs, at least 18 months of follow-up by a BKL-Thalès GP, no prolonged intake of oral corticosteroids and use of at least three canisters of inhaled relievers within a 6 -month period prior to the study period (baseline period). This paper presents data on adult patients ( $\geqslant 17 \mathrm{yrs}$ ).

Patient survey. Patients identified in the database received a survey form from their care giver. Patients answered questions on the level of asthma control (last 2 weeks), asthma symptoms during the last 12 months (occurrence of any asthma crisis? yes/no; occurrence of wheezing? yes/no), and occurrence of visits to ER and hospitalisation for asthma (last 12 months).

\section{Study timelines}

Details have been published previously [3]. Briefly, patients were evaluated over at least 18 months, of which the 12 months preceding the survey were considered as the study period and prior months were considered as the baseline period. Figure 1 illustrates the study timelines.

\section{Study variables}

Data on annual MRU due to asthma were obtained from the computerised database (visits to the GP and

\begin{tabular}{c}
$\begin{array}{c}\text { Identification of } \\
\text { patients in database } \\
\text { and selection }\end{array}$ \\
\hline $\begin{array}{c}\text { Baseline period } \\
\text { ( } \leq 6 \text { months) } \\
\text { (assessment of } \\
\text { severity, from ICS) }\end{array}$
\end{tabular}

Fig. 1.- The study timeline. ICS: inhaled corticosteroids.

all prescribed medications) and the patient survey (visits to ER and hospital contacts for asthma). Other information collected from BKL-Thalès included sex, age, smoking status, access to free healthcare for asthma and presence of comorbid conditions classified by BKL-Thalès into one of the following groups: cardiology, dermatology, endocrinology, gastroenterology, haematology, microbiology, neurology, otorhino laryngology, rheumatology, traumatology, nephrology.

Prescription of inhaled corticosteroids during the baseline period was used as an indicator of asthma severity: high (at least $800 \mu \mathrm{g}$ of budesonide $\mathrm{day}^{-1}$ or equivalent), moderate $\left(<800 \mu \mathrm{g} \cdot \mathrm{day}^{-1}\right)$, low (no use) [3].

The method that was used to assess asthma control was inspired by the definition by CoCKCROFT and Swystun [1] i.e, minimal symptoms and minimal requirement of short-acting relievers: the algorithm for control used in this study is presented in table 1 .

Patients were considered as having good, moderate or poor asthma control using a GINA-derived algorithm that scored asthma symptoms and level of use of inhaled $\beta$-agonists during the last 2 weeks [11].

Specific costs were derived from MRU after multiplying each component by a unit cost for 1997, and were expressed in Euros (€). The unit cost estimate for visits to general practitioners $(22.3 €)$ was obtained from the French Social Security (Caisse Nationale d'Assurance Maladie). The average cost for inpatient stay due to asthma in France $(2,544.4 €)$ was obtained from the Programme de Médicalisation des Systèmes d'Information, the organisation responsible for computing diagnosis-related group costs in France. This cost included all interventions applied during the hospital stay and inpatient therapy. The average cost for an asthma-related ER visit (47.1€) was determined by experts (University of Montpellier,

Table 1. - Level of asthma control (last 15 days)

\begin{tabular}{lccc}
\hline $\begin{array}{l}\text { Score } \# \\
\text { Level of use of inhaled } \\
\quad \begin{array}{l}\# \text {-agonists (short-acting) } \\
\text { puff-day }\end{array}\end{array}$ & $0-1$ & $2-4$ & $>4$ \\
$\begin{array}{l}\text { Occurrence of nocturnal } \\
\quad \text { asthma nights n }\end{array}$ & $0-2$ & $3-8$ & $>8$ \\
$\begin{array}{l}\text { Impairment of usual activities } \\
\quad \text { days with impaired activities n }\end{array}$ & $0-2$ & $3-8$ & $>8$ \\
\begin{tabular}{l} 
Asthma crises n \\
\hline
\end{tabular} & $0-2$ & $3-8$ & $>8$ \\
\hline
\end{tabular}

\#: Total score between $0-8 ; 0$ or 1 : asthma was well controlled; 2 or 3 : asthma was moderately controlled; $>3$ : asthma was poorly controlled. 
Montpellier, France). Unit costs estimates for all prescribed medicines were obtained from the drug industry [12].

\section{Data analysis}

Data analysis was conducted in patients with information available from both BKL-Thalès and the survey. Analysis was conducted in two steps: first, a descriptive analysis of specific and total MRU costs and second, identification of correlates for total MRU cost. This analysis was focused on the relationship between total MRU cost and level of asthma control, allowing for an effect of asthma severity.

Descriptive information on costs. First, distributions of costs for each specific MRU (prescribed medicines, visits to GP, ER visits, hospitalisation) were studied for patients who completed the survey. These specific costs were conditional, i.e. each specific cost was computed only in patients who used the corresponding MRU during the study period. Next, total cost comprising the four MRUs was computed in patients who completed the questionnaire. When patients reported no visit to ER or no hospital admission for asthma, they were considered as having null expenses for this specific outcome. Similar assumptions were made for GP visits or prescriptions records in the database.

Correlates of total medical resource utilisation cost. Univariate analysis. Total MRU cost was studied separately across levels of control (good, moderate, poor), asthma severity (low, moderate, high) and other variables: sex, smoking (ever: yes/ no), age (17-30, 31-40, >40 yrs), presence of comorbid conditions (yes/no), access to free asthma care (yes/no), asthma symptoms in past year (any crisis, any wheezing: yes/no). Wilcoxon and KruskalWallis tests were used to compare costs according to different classes of variables. The relationship between cost and level of control, stratified on the degrees of asthma severity was then studied.

Multivariate analysis. All multivariate analyses were carried out using multiple linear regression, with total MRU cost as the dependant variable. Total MRU cost was log-transformed to normalise its distribution, after discarding patients with null cost. Asthma control and asthma severity were each included in the model with three levels. All other variables associated with total MRU costs in univariate analyses at $\mathrm{p}<0.20$ were also included in the model.

Two linear regression models were defined, M0 and M1. Each model contained asthma severity and asthma control and the cofactors mentioned above. M1 also included the asthma control by asthma severity interaction to assess whether the level of control was modified by the degree of severity, or vice versa. The F-test was used to test whether the inclusion of the interaction improved the goodness of fit. The M0 model was accepted as the final multivariable model if the interaction was not statistically significant.

\section{Results}

\section{Demographics}

In the BKL-Thales database, 1,578 patients met the inclusion criteria. Of these, 1,038 completed the questionnaire $(65.8 \%)$; these patients are described in table 2.

These 1,038 patients did not differ from the other 540 with respect to age, sex, smoking status, asthma severity and access to free asthma care. However comorbid conditions were slightly more common in patients who completed the questionnaire $(\mathrm{p}=0.04)$. In these 1,038 patients, mean age was 36.0 yrs (median 38.0 , range $17-50 \mathrm{yrs}$ ). The level of asthma control could not be determined for 101 of 1,038 responders to questionnaires. Patients with no valid data for asthma control did not differ from their 937 counterparts as to the variables mentioned above. Among 901 patients with complete information for both asthma control and severity, no significant association emerged between these two variables $(p=0.37)$.

\section{Descriptive cost analysis}

Specific conditional medical resource utilisation costs. The distributions of specific MRU costs are displayed in table 3.

Table 2.-Characteristics of 1,038 patients with an evaluable survey

\begin{tabular}{|c|c|c|}
\hline & $\mathrm{n}$ & $\%$ \\
\hline Sex M & 472 & 45.5 \\
\hline \multicolumn{3}{|l|}{ Age yrs } \\
\hline $17-30$ & 311 & 30.0 \\
\hline $31-40$ & 308 & 29.7 \\
\hline $41-50$ & 419 & 40.4 \\
\hline \multicolumn{3}{|l|}{ Ever-smoker } \\
\hline Yes & 270 & 26.0 \\
\hline \multicolumn{3}{|c|}{ Access to free asthma care } \\
\hline Yes & 165 & 15.9 \\
\hline \multicolumn{3}{|c|}{ Presence of comorbid conditions } \\
\hline Yes & 772 & 74.4 \\
\hline \multicolumn{3}{|c|}{ Any asthma crisis (last 12 months) } \\
\hline Yes & 760 & 73.5 \\
\hline No & 274 & 26.5 \\
\hline Missing data & 4 & \\
\hline \multicolumn{3}{|c|}{ Wheezing at any time (last 12 months) } \\
\hline Yes & 745 & 72.0 \\
\hline No & 289 & 28.0 \\
\hline Missing data & 4 & \\
\hline \multicolumn{3}{|c|}{ Level of asthma control (last 2 weeks) ${ }^{\#}$} \\
\hline Good & 515 & 55.0 \\
\hline Intermediate & 294 & 31.4 \\
\hline Poor & 128 & 13.7 \\
\hline Missing data & 101 & \\
\hline \multicolumn{3}{|c|}{ Degree of asthma severity (baseline period) } \\
\hline Low & 388 & 38.8 \\
\hline Moderate & 231 & 23.1 \\
\hline High & 380 & 38.0 \\
\hline Missing data & 39 & \\
\hline
\end{tabular}

\#: based on asthma symptoms; ": based on the dose of inhaled corticosteroids prescribed. 
Table 3. - Distribution of conditional specific medical resource utilisation (MRU) costs

\begin{tabular}{lcccccccc}
\hline & $\mathrm{n}^{\#}$ & $\%$ & Total & Mean & Median & SD & Minimum & Maximum \\
\hline Medicines & 932 & 89.8 & 247321 & 265 & 152 & 308 & 0.5 & 2278 \\
Visits to GP & 1001 & 96.4 & 126969 & 127 & 106 & 105 & 21 & 894 \\
Visits to ER & 119 & 11.5 & 9996 & 84 & 47 & 64 & 47 & 377 \\
Hospitalisation & 94 & 9.0 & 376578 & 4006 & 2544 & 5414 & 2544 & 50889 \\
\hline
\end{tabular}

Data are presented in $€$ unless otherwise stated. GP: general practitioner; ER: emergency room. * number of patients who reported the corresponding MRU; ${ }^{\uparrow}: \%$ out of 1,638 .

A majority of the 1,038 patients visited their GP and received prescriptions for anti-asthma medicines during the study period (table 3). However, specific costs for these two resources accounted for only $17 \%$ and $33 \%$ of total MRU cost, respectively. By contrast, only $9 \%$ of patients were hospitalised but this resource made up $49 \%$ of global expenses (fig. 2). Visits to the ER had little impact on total MRU cost.

Total medical resource utilisation costs. Median cost was $278.0 €$ and 25 th and 75 th percentiles were $133.4 €$ and $587.1 €$, respectively. Total MRU costs ranged from $0-51,674 €$, with an asymmetric distribution (fig. 3). A long distribution tail appeared beyond 1,200€, and 97 patients had their costs concentrated beyond 2,000 €. Based on recent symptoms, these 97 patients had a significantly lower level of control compared to the others $(\mathrm{p}<0.0001)$; they were also more likely to have access to free asthma care and to report asthma crisis during the past 12 months $(p<0.001)$. For these 97 patients, the part of MRU due to hospitalisation exceeded $86 \%$ of the total cost $(376,578 € 1434,309 €)$. In 1,038 patients, 29 had a null value for total cost since they had no asthma-related

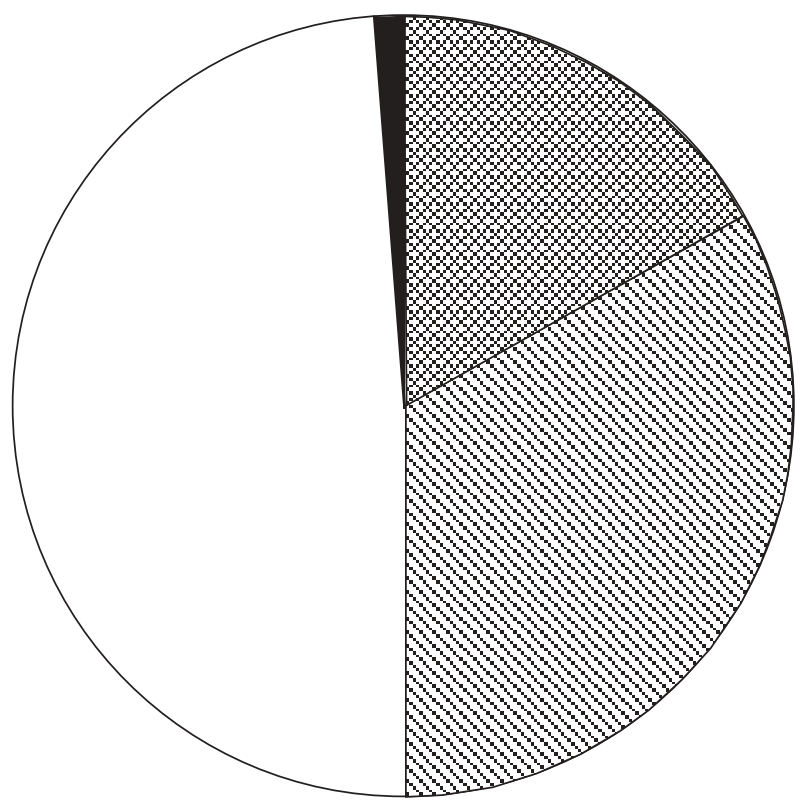

Fig. 2. - Specific expenses in total medical resource utilisation cost $(760,863 €)$ in 1,038 patients. $\square$ : hospitalisation $49 \%$; $\mathbb{\$}$ : asthma medications $33 \%$; visits to general practitioner $17 \%$; $\mathbf{a}$ : visits to emergency room.

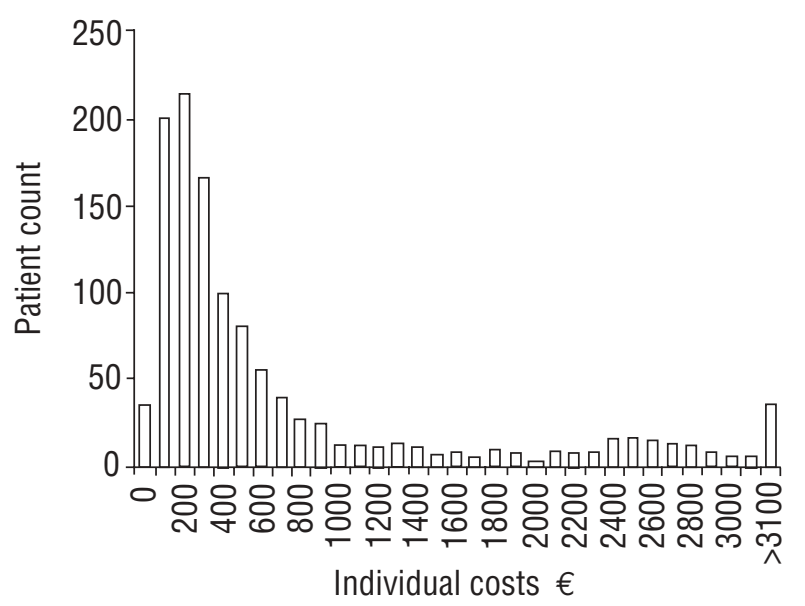

Fig. 3.-Distribution of total medical resource utilisation costs in 1,038 patients.

MRU during the 12-month study. These patients did not differ from their 1,009 counterparts with non-null total MRU costs for any variable of the study except for comorbid conditions $(\mathrm{p}<0.0001)$ : none of the nullcost patients had any comorbid diagnosis recorded.

\section{Correlates of medical resource utilisation costs}

Variations of total MRU costs according to asthma control, asthma severity and other cofactors are displayed in table 4.

Poor control and greater severity were both associated with higher MRU cost. The mean cost for patients with poorly controlled asthma was more than twice the cost for well-controlled patients. A significant increase in the MRU cost, according to levels of control, was also observed in all degrees of asthma severity. There was no difference in total cost between 937 patients who mentioned their asthma control and the 101 others who did not (Wilcoxon test, $\mathrm{p}=0.78$ ), or between patients with and without valid data for asthma severity (Wilcoxon test, $\mathrm{p}=0.90$ ). Age and access to free asthma care was also significantly associated with increased total MRU cost.

Multivariate analysis. Multivariate analyses were conducted in 872 patients with non-null costs (log transformation) and valid missing data for all variables included in models. Given the high correlation between the two variables reporting occurrence of asthma 
Table 4. - Univariate analysis for total medical resource utilisation (MRU) cost in 1038 patients

\begin{tabular}{|c|c|c|c|c|c|c|}
\hline & $\mathrm{n}$ & 25th percentile & Median & 75th percentile & Mean & Statistical test \\
\hline \multicolumn{7}{|l|}{ Sex } \\
\hline Male & 472 & 137.6 & 281.3 & 580.3 & 696.9 & \multirow[t]{2}{*}{$\mathrm{p}=0.37^{\#}$} \\
\hline Female & 566 & 123.7 & 273.6 & 592.8 & 763.1 & \\
\hline \multicolumn{7}{|l|}{ Age yrs } \\
\hline $17-30$ & 311 & 90.6 & 214.2 & 410.9 & 553.0 & \multirow{3}{*}{$\mathrm{p}<0.0001^{\oplus}$} \\
\hline $31-40$ & 308 & 127.6 & 257.7 & 575.6 & 714.0 & \\
\hline $41-50$ & 419 & 177.0 & 347.4 & 710.9 & 880.6 & \\
\hline \multicolumn{7}{|l|}{ Ever-smoker } \\
\hline Yes & 270 & 136.7 & 291.7 & 594.8 & 714.9 & \multirow[t]{2}{*}{$\mathrm{p}=0.32^{\#}$} \\
\hline No & 768 & 130.0 & 275.1 & 567.6 & 739.3 & \\
\hline \multicolumn{7}{|c|}{ Access to free asthma care } \\
\hline Yes & 165 & 296.7 & 541.3 & 1406.7 & 1240.1 & \multirow{2}{*}{$\mathrm{p}<0.0001^{\#}$} \\
\hline No & 873 & 116.7 & 245.8 & 502.3 & 637.1 & \\
\hline \multicolumn{7}{|c|}{ Presence of comorbid conditions } \\
\hline Yes & 772 & 158.6 & 313.6 & 646.0 & 790.3 & \multirow{2}{*}{$\mathrm{p}<0.0001^{\#}$} \\
\hline No & 266 & 65.6 & 167.4 & 405.4 & 566.4 & \\
\hline \multicolumn{7}{|c|}{ Any asthma crisis (last 12 months) } \\
\hline Yes & 760 & 140.9 & 296.1 & 638.2 & 794.6 & \multirow[t]{3}{*}{$\mathrm{p}<0.0001^{\#}$} \\
\hline No & 274 & 104.3 & 236.6 & 456.7 & 535.1 & \\
\hline Missing data & 4 & 554.0 & 2185.9 & 4644.6 & 2599.3 & \\
\hline \multicolumn{7}{|c|}{ Any wheezing (last 12 months) } \\
\hline Yes & 745 & 140.9 & 297.9 & 650.7 & 794.8 & \multirow[t]{3}{*}{$\mathrm{p}<0.0001^{\#}$} \\
\hline No & 289 & 104.3 & 236.6 & 477.9 & 579.1 & \\
\hline Missing data & 4 & 139.7 & 193.6 & 588.9 & 364.3 & \\
\hline \multicolumn{7}{|c|}{ Degree of asthma severity (baseline period) } \\
\hline Low & 388 & 89.8 & 193.3 & 349.0 & 558.7 & \multirow{4}{*}{$\mathrm{p}<0.0001^{\curvearrowleft}$} \\
\hline Moderate & 231 & 155.8 & 347.2 & 713.7 & 984.3 & \\
\hline High & 380 & 176.4 & 370.9 & 746.8 & 771.9 & \\
\hline Missing data & 39 & 170.9 & 288.3 & 577.7 & 600.3 & \\
\hline \multicolumn{7}{|c|}{ Level of control (last 2 weeks) } \\
\hline Good & 515 & 98.8 & 229.4 & 479.9 & 549.8 & \multirow[t]{4}{*}{$\mathrm{p}<0.0001^{\oplus}$} \\
\hline Moderate & 294 & 163.2 & 311.6 & 611.9 & 746.3 & \\
\hline Poor & 128 & 208.7 & 459.6 & 1554.2 & 1451.3 & \\
\hline Missing data & 101 & 131.1 & 261.8 & 507.9 & 718.0 & \\
\hline \multicolumn{7}{|c|}{ Control stratified on severity ${ }^{+}$} \\
\hline Low severity ${ }^{f}$ & & & & & & \\
\hline Good control & 199 & 81.0 & 157.7 & 318.7 & 409.3 & \multirow{3}{*}{$\mathrm{p}=0.0009^{\bullet}$} \\
\hline Moderate control & 101 & 109.2 & 236.6 & 402.8 & 497.1 & \\
\hline Poor control & 54 & 139.9 & 297.2 & 864.8 & $1,453.4$ & \\
\hline \multicolumn{7}{|l|}{ Moderate severity** } \\
\hline Good control & 113 & 137.8 & 324.0 & 621.9 & 958.4 & \multirow[t]{3}{*}{$\mathrm{p}=0.07^{\bullet}$} \\
\hline Moderate control & 66 & 199.9 & 403.3 & 748.1 & 853.8 & \\
\hline Poor control & 21 & 300.4 & 561.8 & 1175.8 & 1491.8 & \\
\hline High severity $^{\# \#}$ & & & & & & \\
\hline Good control & 184 & 138.4 & 308.9 & 584.5 & 478.8 & $\mathrm{p}<0.0001^{\Uparrow}$ \\
\hline Moderate control & 117 & 186.2 & 441.8 & 934.6 & 927.0 & \\
\hline Poor control & 46 & 344.4 & 635.2 & 1998.1 & 1379.8 & \\
\hline
\end{tabular}

All tests were computed without missing values. ${ }^{\#}$ : Wilcoxon test; ${ }^{\top}$ : Kruskal-Wallis test; ${ }^{+}$: computed on 901 patients with valid data for both control and severity; $f: n=354 ; * *: n=200 ;{ }^{\# \#}: \mathrm{n}=347$.

symptoms during the study period (Chi-squared (one degree of freedom $=238, p<0.0001)$, "asthma crisis" was the only symptom variable included in the model, since it was more closely correlated to total MRU cost than "wheezing". Both M0 and M1 included age, presence of comorbid conditions, access to free asthma care, level of control and degree of severity. M1 included the four additional interaction terms. Accepting these four interaction terms did not yield significant improvement $\left(\mathrm{F}_{4,862}=0.80, \mathrm{p}=0.90\right)$; none of the four interaction coefficients reached significance (data not reported). Consequently, M0 was retained as the final multivariate linear model (table 5). Most univariate results were confirmed.

\section{Discussion}

The level of asthma control as measured by recent symptoms is a major correlate of total MRU, including drug therapy, ambulatory care and hospital care in persistent asthma, increasing substantially with lesser levels of control. Poorly controlled asthma resulted in a significant 2.5 -fold increase in MRU costs, compared to well-controlled disease. Asthma severity, as judged by the prescribed doses of inhaled corticosteroids in the prestudy period, was also associated with a significant increase in MRU costs independently of other cofactors. Finally, the following 
Table 5. - Multiple regression model (MO) for log-transformed cost variable

\begin{tabular}{|c|c|c|c|c|}
\hline & Parameter value & SD & t-value & p-value \\
\hline \multicolumn{5}{|l|}{ Age } \\
\hline $31-40$ yrs $^{\#}$ & 0.06 & 0.10 & 0.63 & 0.53 \\
\hline$\geqslant 41 \mathrm{yrs}^{\#}$ & 0.34 & 0.09 & 3.62 & 0.0003 \\
\hline Access to free asthma care yes/no & 0.47 & 0.11 & 4.47 & $<0.0001$ \\
\hline Presence of comorbid conditions yes/no & 0.44 & 0.09 & 4.89 & $<0.0001$ \\
\hline Asthma crisis (study period) & 0.35 & 0.09 & 3.90 & $<0.0001$ \\
\hline Moderate asthma severity & 0.47 & 0.10 & 4.73 & $<0.0001$ \\
\hline High asthma severity & 0.48 & 0.09 & 5.55 & $<0.0001$ \\
\hline Moderate asthma control yes $/$ no $^{+}$ & 0.25 & 0.09 & 2.95 & 0.003 \\
\hline Poor asthma control (yes/no) ${ }^{+}$ & 0.61 & 0.12 & 5.08 & $<0.0001$ \\
\hline
\end{tabular}

\#: reference age 17-30 yrs; ${ }^{\text {ๆ}: ~ r e f e r e n c e ~ l o w ~ d e g r e e ~ o f ~ a s t h m a ~ s e v e r i t y ; ~}{ }^{+}$: reference good level of asthma control. Adjusted $\mathrm{R}^{2}=0.17, \mathrm{p}<0.0001 . \mathrm{n}=872$.

factors were also associated with increased cost of care: age, access to free asthma care, presence of comorbid conditions and asthma symptoms in the past year.

Both the level of control and degree of severity, as measured in this study, are correlates of MRU. Level of control and asthma severity were identified from distinct sources and at different points in time: prescription information for severity, i.e. the dose of inhaled corticosteroids prescribed by the family physician before the study period; and patient data for assessment of control, i.e. the patient's response to a specific questionnaire at the end of the study period. The level of control was assessed for a 2 -week period at the end of the study period. However, this level of control may reflect the patients' attitude towards asthma medications drug observance and avoidance of risk factors throughout the study period. In a recent survey, Vollmer et al. [13] found that a short-term control index was significantly related to healthcare utilisation in a consecutive 12-month period.

Asthma severity was assessed from average doses of prescribed inhaled corticosteroids during a baseline prestudy period (fig. 1). The marker of severity in this study was correlated with access to free healthcare for asthma $(\mathrm{p}=0.0004)$, number of prescriptions of oral corticosteroids $(\mathrm{p}=0.01)$ and number of different classes of asthma medications prescribed during the 12 -month study period $(\mathrm{p}<0.0001)$. Finally, the significant increase of MRU costs across degrees of severity is consistent with recent data from SERRABATLlES et al. [14]. In that study, severity was based on the International Consensus Report on Diagnosis and Treatment for Asthma [15].

Control of asthma also had an important effect on costs, independently of severity. Poor control was associated with higher MRU in the preceding 12 months, suggesting that a significant part of the burden of asthma could be prevented with improved disease management. The comparison of MRU across levels of control within different degrees of severity is of interest. In all severity categories, costs increased significantly with decreasing levels of control. In each category, costs for "well-controlled" patients could be interpreted as indicative of the "minimal" costs of asthma care according to disease severity. A priori, such costs are nonpreventable, in contrast to the costs computed in groups with lesser levels of control.

Age correlation with cost is not surprising, since age is a known risk factor for resource consumption in asthma, as in other conditions [16]. The significant relationship between comorbid conditions and cost was less expected in this rather young population (17-50 yrs) where asthma was the major morbidity. It suggests that conditions linked to asthma may have an impact on resource consumption [17]. Concomitant psychiatric troubles have been shown to be associated with increased asthma morbidity, and they may contribute to increased costs [18]. Having access to free asthma care also resulted in higher costs of MRU. These patients were older and had more comorbid conditions, but multivariate analyses suggested that access to free asthma care was associated with higher costs independent of these characteristics. This finding is in agreement with the purposes of access to free asthma care in France, provided to patients with more severe disease, independent of their socioeconomic status, after review of their medical history by Social Security experts.

Only crude comparisons can be made between the data presented here and information available for other countries. BARNES et al. [19] made a comparison of direct costs between countries; depending on the country and the study, hospital contacts comprised between $18-79 \%$ of direct costs, i.e. generally a lesser portion of the costs of MRU than in this study. BARNES et al. [19] found that improved control was associated with an increase in drug costs and more visits to the GP. It should be stressed that, as a result of the selection of patients with persistent asthma, the present data did not allow valid estimates of the total asthma burden in the French population, in contrast to data published by other investigators [19-21]. Another effect of the selection of patients with persistent asthma may have been the relatively high incidence of hospital contacts. Nevertheless, this is also the result of efforts to collect data on this outcome directly from patients. The current authors have indeed demonstrated that care givers are not optimally informed of outcomes in asthma patients, and using family physician data may result in underestimates of the hospital-contacts incidence [22].

These points underline some limitations of using 
a GP prescription database in asthma outcomes research. However, important advantages should also be acknowledged, i.e. that such databases may be considered as a more valid tool to assess asthma severity than drug dispensing databases, since data are available on actual $\mathrm{GP}^{\prime} \mathrm{s}$ prescriptions of inhaled corticosteroids. Those prescriptions may be considered as being a reflection of the care givers' instant perception of asthma control, at least in settings and at times where such prescriptions were issued with some reluctance [23]. A selection criteria prescribed was at least three canisters of inhaled $\beta$-agonists during the 6-month period before the onset of the study. This could be considered as high $\beta$-agonists consumption, but it was consistent with $\beta$-agonists prescription patterns by GPs in France until recently.

This study had some other limitations. To compute medication costs, several assumptions were made, for example that patients took their prescriptions. Average costs were used to estimate the impact of admission to hospital for asthma, since there was no access to individual inpatient hospital-resource consumption data. Also, there may be recall bias in the responses to the survey questions, e.g. with some patients over- or underestimating their rate of hospital admission. A selection bias could affect the results if there was a systematic, nonrandom, factor influencing the patient's decision to complete and return the questionnaire; 1,038 responders to questionnaires would then be different from 540 nonresponders. However, there were no significant differences between these two groups in demographic variables and asthma severity, though records of comorbid conditions were slightly higher among the 1,038 responders $(\mathrm{p}<0.04)$. Of 1,038 participants who completed the questionnaire, 101 did not answer specific questions for asthma control. This could represent another selection bias. However, patients with missing information on control did not differ from 937 others for costs or any variable in the study. If a selection bias cannot be excluded, its influence should be limited. Multivariate analyses were conducted in only 872 patients with non-null total MRU cost and valid data for all covariates. Except for comorbid conditions, these 872 subjects did not differ from their 166 counterparts for any other studied variables (data not reported). Furthermore, all multivariate results were consistent with univariate analyses.

In the final linear model, global $\mathrm{R}^{2}$ did not exceed 0.17 . Only a limited number of correlates for costs were identified. For example, the authors had no information on socioeconomic status, on education level, or on the attitude of the patients [24]. However, a gradient of resource consumption was identified according to increasing severity or decreasing control, and this provided support to the assessment of these two diseases characteristics, and their relationship to resource consumption.

In summary, the results suggest that the major part of the cost burden of asthma is a consequence of both poor control and greater severity, especially for major outcomes, such as hospital admissions. Improvement in asthma control through improved disease management could potentially result in significant savings, in patient morbidity and costs to society [25]. The findings also confirm that information obtained directly from patients is a useful addition to database information [3]. The linkage of medical records to a specific patient survey may help to understand the complex relationship between severity and control in asthma, and to identify preferred areas of interventions to relieve the burden of asthma.

\section{References}

1. Cockcroft DW, Swystun VA. Asthma control versus asthma severity. J Allergy Clin Immunol 1996; 98: 1016-1018.

2. Osborne ML, Vollmer WM, Pedula KL, Wilkins J, Buist S, O'Hollaren M. Chest 1999; 115: 85-91.

3. Van Ganse E, Boissel JP, Gormand F, Ernst P. Level of control and hospital contacts in persistent asthma. J Asthma 2001; 38: 637-643.

4. Godard P, Clark TJH, Busse WW, et al. Clinical assessment of patients. Eur Respir J Suppl 1998; 26: $2 \mathrm{~S}-5 \mathrm{~S}$.

5. Rabe KF, Vermeire PA, Soriano JB, Maier WC. Clinical management of asthma in 1999: the asthma insights and reality in Europe study. Eur Respir $J$ 2000; 16: 802-807.

6. Hanania NA, David-Wang A, Kesten S, Chapman KR. Factors associated with emergency department dependence of patients with asthma. Chest 1997; 111: 290-295.

7. Van Ganse E, Hubloue I, Vincken W, Leufkens HGM, Gregoire J, Ernst P. Actual use of inhaled corticosteroids and risk of hospitalisation: a casecontrol study. Eur J Clin Pharmacol 1997; 51: 449454.

8. Stempel DA, Durcannin-Robbins JF, Hedblom EC, Woolf R, Sturm LL, Stempel AB. Drug utilisation evaluation identifies costs associated with high use of beta-adrenergic agonists. Ann Allergy Asthma Immunol 1996; 76: 153-158.

9. Lanes SF, Birmann BM, Walker AM, et al. Characterisation of asthma management in the Fallon Community Health Plan from 1988 to 1991. PharmacoEconomics 1996; 10: 378-385.

10. Liard R, Leynaert B, Zureik M, Beguin FX, Neukirch F. Using global initiative for asthma guidelines to assess asthma severity in populations. Eur Respir $J$ 2000; 16: 615-620.

11. Global Initiative for Asthma (GINA). Global strategy for asthma management and prevention. NHLBI/ WHO Workshop Report, March 1993. National Institute of Health, Publication Number 95-3659. January 1995 .

12. Dictionnaire Vidal 1997. Paris, Éditions du Vidal, 1997.

13. Vollmer WM, Markson LE, $\mathrm{O}^{\prime}$ Connor E, Frazier EA, Berger M, Buist AS. Association of asthma control with health care utilization: a prospective evaluation. Am J Respir Crit Care Med 2002 15; 165: 195-199.

14. Serra-Batlles J, Plaza V, Morejon E, Comella A, Brugues J. Costs of asthma according to the degree of severity. Eur Respir J 1998; 12: 1322-1326.

15. International Consensus Report on Diagnosis and 
Treatment of Asthma. Clin Exp Allergy 1992; 22: $1-72$.

16. Weiss KB, Sullivan SD, Lyttle CS. Trends in the cost of illness for asthma in the United States, 1985-1994. J Allergy Clin Immunol 2000; 106: 493-499.

17. Weiss KB. The health economics of asthma and rhinitis. I. Assessing the economic impact. $J$ Allergy Clin Immunol 2001; 107: 3-8.

18. Joseph KS, Blais L, Ernst P, Suissa S. Increased morbidity and mortality related to asthma among asthmatic patients who use major tranquillisers. $B M J$ 1996; 312: 79-81.

19. Barnes PJ, Jonsson B, Klim JB. The costs of asthma. Eur Respir J 1996; 9: 636-642.

20. Weiss KB, Gergen PJ, Hodgson TA. An economic evaluation of ashma in the United States. $N$ Engl J Med 1992; 326: 862-866.
21. Krahn MD, Berka C, Langlois P, Detsky A. Direct and indirect costs of asthma in Canada. Can Med Assoc J 1996; 154: 821-831.

22. Van Ganse E, Leufkens HGM, Vincken W, et al. Assessing asthma management from interviews of patients and family physicians. J Asthma 1997; 34 : 203-209.

23. Bousquet J, Knani J, Henry C, et al. Undertreatment in a nonselected population of adult patients with asthma. J Allergy Clin Immunol 1996; 98: 514 521.

24. Adams RJ, Smith BJ, Ruffin RE. Patient preferences for autonomy in decision making in asthma management. Thorax 2001; 56: 126-132.

25. Gibson PG. Monitoring the patient with asthma: an evidence-based approach. J Allergy Clin Immunol 2000; 106: 17-26. 